\title{
Correlations in V1 Are Reduced by Stimulation Outside the Receptive Field
}

\author{
(1) Adam C. Snyder, ${ }^{1,2}$ Michael J. Morais, ${ }^{1,3}$ Adam Kohn, ${ }^{4,5}$ and ${ }^{-}$Matthew A. Smith ${ }^{1,2,3}$ \\ ${ }^{1}$ Department of Ophthalmology, ${ }^{2}$ Center for the Neural Basis of Cognition, and ${ }^{3}$ Department of Bioengineering, University of Pittsburgh, Pittsburgh, \\ Pennsylvania 15213, and ${ }^{4}$ Dominick Purpura Department of Neuroscience and 5 Department of Ophthalmology and Visual Sciences, Albert Einstein College \\ of Medicine, New York, New York 10461
}

The trial-to-trial response variability of nearby cortical neurons is correlated. These correlations may strongly influence population coding performance. Numerous studies have shown that correlations can be dynamically modified by attention, adaptation, learning, and potent stimulus drive. However, the mechanisms that influence correlation strength remain poorly understood. Here we test whether correlations are influenced by presenting stimuli outside the classical receptive field (RF) of visual neurons, where they recruit a normalization signal termed surround suppression. We recorded simultaneously the activity of dozens of cells using microelectrode arrays implanted in the superficial layers of V1 in anesthetized, paralyzed macaque monkeys. We presented annular stimuli that encircled- but did not impinge upon - the RFs of the recorded cells. We found that these "extra-classical" stimuli reduced correlations in the absence of stimulation of the RF, closely resembling the decorrelating effects of stimulating the RFs directly. Our results suggest that normalization signals may be an important mechanism for modulating correlations.

Key words: electrophysiology; extra-classical receptive field; population coding; spike count correlation; surround suppression; V1

\section{Introduction}

Repeated presentations of a sensory stimulus produce neuronal spiking responses that differ substantially from trial to trial. This response variability is correlated between nearby neurons with similar functional properties (Cohen and Kohn, 2011): a stronger than average response in one cell on a particular trial is likely to be accompanied by a similar enhancement in other nearby cells. These correlations in trial-to-trial responses may strongly influence population coding performance (Averbeck et al., 2006).

Recent work has shown that correlations are not fixed in strength; instead they depend on context (Kohn et al., 2009). For instance, in primary visual cortex (V1), the presentation of a high-contrast stimulus in the receptive fields (RFs) of a pair of neurons reduces the strength of long timescale correlations of their spontaneous activity (Kohn and Smith, 2005; Smith and Kohn, 2008; Huang and Lisberger, 2009; Tan et al., 2014). In V4, attention has been shown to weaken correlations, which may

Received Feb. 24, 2014; revised May 27, 2014; accepted June 20, 2014.

Author contributions: A.C.S., M.J.M., A.K., and M.A.S. designed research; A.C.S., M.J.M., A.K., and M.A.S. performed research; A.C.S., M.J.M., and M.A.S. analyzed data; A.C.S., M.J.M., A.K., and M.A.S. wrote the paper.

A.C.S. was supported by an institutional National Institutes of Health (NIH) postdoctoral training fellowship through the University of Pittsburgh (T32NS007391) and an individual NIH fellowship (F32EY023456). M.J.M. was supported by an NIH undergraduate research training fellowship through the University of Pittsburgh's Program in Neural Computation (R90DA023428). A.K. was supported by NIH Grant R01EY016774 and Research to Prevent Blindness. M.A.S. was supported by NIH grants ROOEY018894, R01EY022928, and P30EY008098; a career development grant and an unrestricted award from Research to Prevent Blindness; and the Eye and Ear Foundation of Pittsburgh.

The authors declare no competing financial interests.

Correspondence should be addressed to Matthew A. Smith, Department of Ophthalmology, University of Pittsburgh, Eye and Ear Institute, 203 Lothrop Street, 9th Floor, Pittsburgh, PA 15213. E-mail: smithma@pitt.edu.

DOI:10.1523/JNEUROSCI.0762-14.2014

Copyright $\odot 2014$ the authors $\quad 0270-6474 / 14 / 3411222-06 \$ 15.00 / 0$ underlie its beneficial effects on performance (Cohen and Maunsell, 2009; Mitchell et al., 2009). Learning (Gu et al., 2011; Jeanne et al., 2013) and adaptation (Gutnisky and Dragoi, 2008; Adibi et al., 2013) have also been shown to alter correlations. Indeed, changes in correlation strength and structure may be an important component of how sensory processing adjusts to meet the demands of a particular environment or situation.

While there is good evidence that correlations are flexible, the mechanisms that control their strength remain unclear. To date, demonstrations of altered correlations have focused on manipulations that activate the recorded neurons. Here we test the possibility that stimuli that do not directly drive a pair of neurons can also alter their correlation. We focus on the modulatory influence of visual stimuli placed outside the classical RF-in the surround. The influence of the surround has been studied extensively in primary visual cortex (Angelucci and Bressloff, 2006), and its effects are suggested to be a form of divisive normalization (Heeger, 1992; Cavanaugh et al., 2002; Coen-Cagli et al., 2012), a canonical cortical computation (Carandini and Heeger, 2012). We find that surround stimulation can suppress correlations, much like stimuli within the RF. This effect was observed for surround stimulation even in the absence of stimulation of the $\mathrm{RF}$. This suggests that the mechanisms underlying divisive normalization influence the strength of pairwise correlations, and we propose that this may account for at least some previous findings of flexible correlations.

\section{Materials and Methods}

Subjects and electrophysiological recordings. The basic experimental procedures have been described previously (Smith and Kohn, 2008). Anesthesia was induced with ketamine $(10 \mathrm{mg} / \mathrm{kg})$ and maintained during 


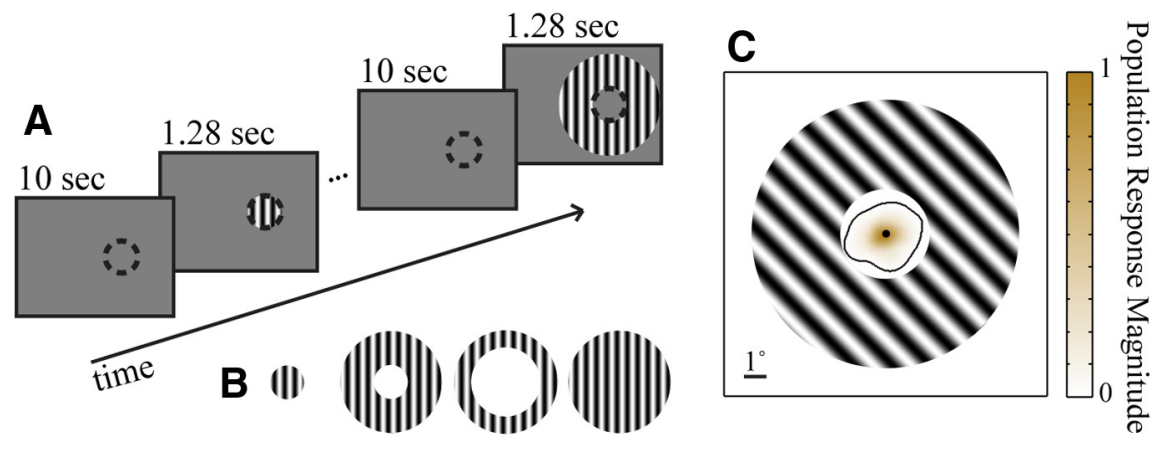

Figure 1. A, Schematic time line of stimulus sequence. Grating stimuli were presented for $1.28 \mathrm{~s}$, centered on the recorded RF area (represented by the dashed circle, not actually present in the stimulus). Gratings were separated by $10 \mathrm{~s}$ intervals of blank screens, except when noted otherwise in the text. B, Stimulus types. From left to right: $4^{\circ} \mathrm{RF}$ grating, near annulus, far annulus, and $12^{\circ}$ grating (the $12^{\circ}$ grating was included for 3 of the 5 array implants). C, Map of normalized aggregate RF area plotted with a superimposed near annulus for reference. The black contour line encloses $99 \%$ of all stimulus-evoked responses.

preparatory surgery with isoflurane $\left(1.0-2.5 \%\right.$ in $\left.95 \% \mathrm{O}_{2}\right)$. Sufentanil citrate $(6-18 \mu \mathrm{g} / \mathrm{kg} / \mathrm{h}$, adjusted as needed for each animal) was injected intravenously to maintain anesthesia during recordings. Vecuronium bromide $(0.15 \mathrm{mg} / \mathrm{kg} / \mathrm{h})$ was used to suppress eye movements. All procedures were approved by the Albert Einstein College of Medicine at Yeshiva University and followed the guidelines in the United States Public Health Service Guide for the Care and Use of Laboratory Animals.

We made five array implants in V1 of five hemispheres of four adult male cynomolgus (Macaca fascicularis) monkeys. Implants were made on the operculum of $\mathrm{V} 1 \sim 8 \mathrm{~mm}$ posterior to the lunate sulcus and $10 \mathrm{~mm}$ lateral to midline, where neuronal RFs are $2-3^{\circ}$ eccentric in the lower visual field and $\sim 1^{\circ}$ in diameter (Cavanaugh et al., 2002). We recorded neural activity with "Utah" arrays (Blackrock Microsystems), using methods reported previously (Kelly et al., 2007). Signals from each microelectrode were amplified and bandpass filtered $(250 \mathrm{~Hz}$ to $7.5 \mathrm{kHz})$. Waveform segments that exceeded a threshold were digitized $(30 \mathrm{kHz})$.

Waveform segments were sorted off-line using an automated algorithm with manual refinement (Smith and Kohn, 2008). We computed the signal-to-noise ratio (SNR) of each candidate unit as the ratio of the average waveform amplitude to the SD of the waveform noise (Kelly et al., 2007). Candidates with an SNR $<2.75$ were discarded as multiunit activity. We also eliminated neurons whose best grating stimulus did not evoke a response of at least 2 spikes/s ( 92 units removed). This procedure yielded a total of 375 cells recorded from 299 distinct electrodes (55-91 neurons/implant). Each neuron was paired with all other simultaneously recorded neurons, excluding pairs from the same electrode, providing 14,360 pairs. Changing our selection criteria for SNR and response rate did not alter meaningfully the reported results.

Stimuli. We presented visual stimuli on a calibrated CRT monitor $(1024 \times 768$ pixels, $100 \mathrm{~Hz}$ refresh) placed $110 \mathrm{~cm}$ from the animal, using custom software (EXPO). We presented sinusoidal gratings centered on the aggregate RF of the array implants. We used gratings of $4^{\circ}$ diameter (Fig. 1) and two annular sinusoidal gratings, both with $12^{\circ}$ outer diameters but one with a $4^{\circ}$ inner diameter ("near annulus") and the other an $8^{\circ}$ inner diameter ("far annulus"). Post hoc analysis revealed that units on only 1 of the 299 channels in the analysis had response fields that slightly overlapped the near annulus. Gratings were full contrast, and presented at four equally spaced orientations ( $45^{\circ}$ increments) for $1.28 \mathrm{~s}$ with a $10 \mathrm{~s}$ interstimulus interval. The spatial frequency $(1.3 \mathrm{cpd})$ and temporal frequency $(6.25 \mathrm{~Hz})$ values were chosen to drive well parafoveal V1 neurons (Smith et al., 2002). Stimuli were presented monocularly. In a subset of experiments (three array implants), we included a $12^{\circ}$ diameter grating, with otherwise identical properties, to measure surround suppression.

For experiments involving gratings presented to the ipsilateral field, we used $1.28 \mathrm{~s}$ stimulus durations separated by $1.5 \mathrm{~s}$ blank intervals. This shorter interstimulus interval allowed us to maximize the number of stimulus presentations. To avoid contamination due to offset responses from the preceding trial in these experiments, we restricted our measurements of spontaneous activity to the $600 \mathrm{~ms}$ preceding each stimulus. To maintain time bins of equal length, we also restricted the analysis of the stimulus period to the first $600 \mathrm{~ms}$. Note that while spike count correlation $\left(r_{s c}\right)$ is dependent on the length of the time period over which spikes are counted, we have previously shown that its magnitude asymptotes for time periods exceeding $200 \mathrm{~ms}$ (Smith and Kohn, 2008).

Analysis. The $r_{s c}$ is the Pearson correlation coefficient of the evoked spike counts of two cells to repeated presentations of a particular stimulus: it captures shared trial-to-trial variability. We calculated $r_{s c}$ separately for each stimulus orientation and then averaged these values to derive a single $r_{s c}$ value for each stimulus type for each pair of neurons. We used Fisher's $r$-to- $Z$ transformation before performing statistical evaluation of $r_{s c}$ values.

We calculated the average $r_{s c}$ across all pairs within each array implant, and then averaged across the implants, weighted by the number of neurons on each implant. We weighted in this fashion rather than by the number of pairs for two reasons. First, the contribution of each array to the total number of pairs is nonlinearly related to the number of individual neurons from each array. Weighting by neuron number enables a consistent relative weight of each array for single neuron measurements (e.g., firing rate) and correlation data. Second, since the many correlations derived from all of the pairings of neurons are not independent (Olkin, 1981), treating each pair as an independent degree of freedom could violate assumptions of the statistical tests. It is more conservative to define the degrees of freedom using the number of individual neurons.

We compared firing rate and $r_{s c}$ across three stimulus conditions $\left(4^{\circ}\right.$ RF grating, near annulus and far annulus; Fig. 1), and across the two time periods (baseline vs stimulation) using a two-way ANOVA. For the factor of "stimulus," significant $F$ tests $(p<0.05)$ were followed by post hoc pairwise repeated-measures $t$ tests (two-tailed, $\alpha=0.017$, reflecting Bonferroni correction). The mean squared deviations and degrees of freedom for the $F$ tests reflected weighting by the number of neurons, rather than the number of pairs.

To quantify the latency of changes in correlation strength following stimulus onset, we used a bootstrap resampling approach. First, we calculated $r_{s c}$ throughout the trial in $100 \mathrm{~ms}$ windows shifted by $2 \mathrm{~ms}$. Next, we measured the mean and SD for $r_{s c}$ and firing rate across all prestimulus time windows. We estimated the onset latency of a change in $r_{s c}$ as the midpoint of the first $100 \mathrm{~ms}$ time window that exceeded three SDs above or below the mean of the baseline. We then created a surrogate dataset of equal size by resampling from our original 14,360 pairs of neurons with replacement, and estimated latencies for these data. The entire procedure was repeated 5000 times to create an estimate for the sampling distribution of latencies for each condition (the "bootstrap distributions"). The means of these bootstrap distributions are our estimates of the onset latencies, and the 0.5 and 99.5 percentiles of these distributions form $99 \%$ confidence intervals (CIs) for the latencies. To perform pairwise comparisons of onset latencies, we took the difference between the onset latencies for the two conditions of interest for each surrogate dataset; the distribution of these differences can be used to derive a $p$ value by finding the widest confidence interval for the mean that does not include zero.

\section{Results}

We recorded from 375 V1 neurons with five microelectrode arrays implanted in four anesthetized, paralyzed macaque monkeys. This provided 14,360 neuronal pairs. We measured responses to three sets of visual stimuli: $4^{\circ}$ sinusoidal gratings centered on the aggregate RF (termed RF gratings), and two sets of grating annuli that did not impinge on the RF (outer diameter of $12^{\circ}$, inner diameters of 4 and $8^{\circ}$; Fig. 1). Each stimulus was presented at four orientations. We measured firing rate and $r_{s c}$ 

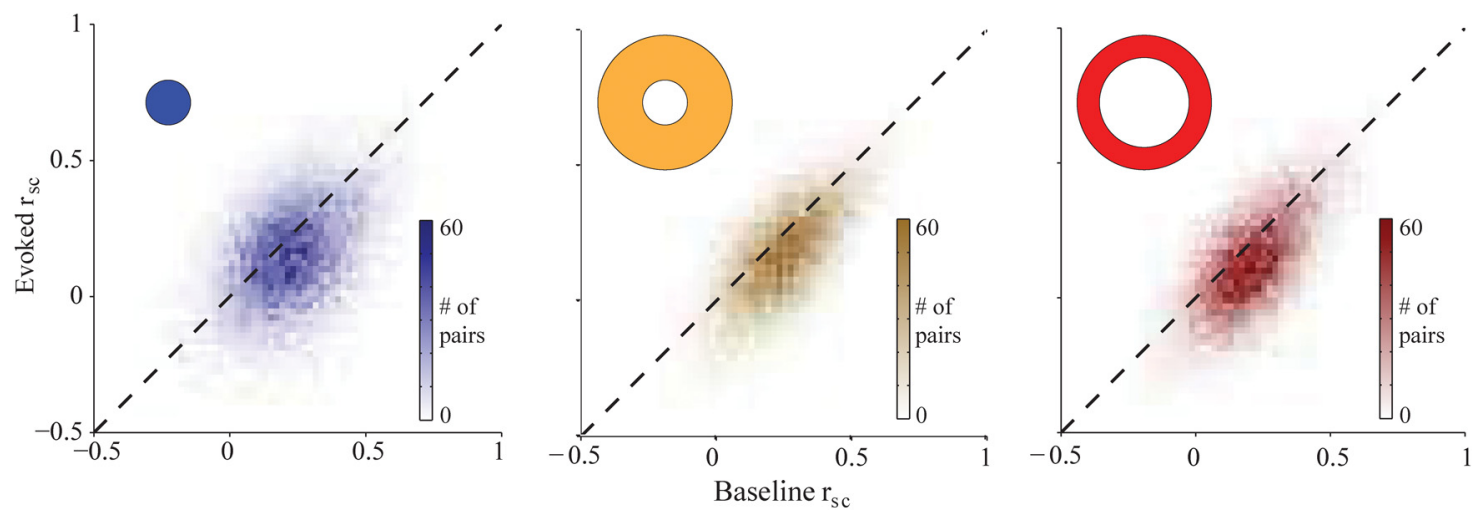

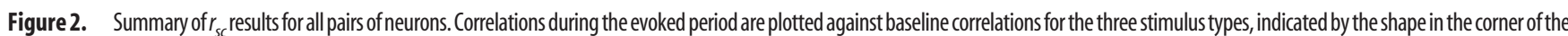
plot. Note that for each condition the distribution lies predominantly below the diagonal, indicating that correlations were weaker during the stimulus period than during the baseline period.

during the $1.28 \mathrm{~s}$ of visual stimulation, and in $1.28 \mathrm{~s}$ epochs preceding stimulus onset.

We found that $r_{s c}$ was reduced by the presentation of a stimulus (Fig. 2). Across all conditions and pairs, the average $r_{s c}$ was $0.184 \pm 0.007$ ( \pm SEM $)$, significantly lower than during the baseline period immediately preceding stimulus onset $(0.212 \pm$ 0.007. $\left.F_{(1,2244)}=16.28, p \ll 0.001\right)$. Critically, this decrease was observed not only for stimuli inside the RFs of the recorded neurons, but also for the two sets of annuli (all $p s \ll 0.001$ ). The RF gratings caused the strongest drop in correlation strength $\left(\Delta r_{s c}=\right.$ $-0.042 \pm 0.005)$, followed by the far $\left(\Delta r_{s c}=-0.029 \pm 0.004\right)$ and near annuli $\left(\Delta r_{s c}=-0.017 \pm 0.004\right)$. The effect size was different across stimuli (interaction: $F_{(2,2244)}=18.62, p \ll$ 0.001 ), but none of the pairwise comparisons was significantly different when corrected for multiple comparisons. Thus, we conclude that stimulus drive both within and outside the RF reduced the strength of correlations.

It has previously been shown that the value of $r_{s c}$ may be underestimated at low firing rates (de la Rocha et al., 2007; Cohen and Kohn, 2011). Our grating stimulus in the RF caused firing rates to increase from $6.802 \pm 0.029$ to $8.774 \pm 0.035 \mathrm{~Hz}$; the relatively small increase is due to suppression by the $4^{\circ}$ grating and averaging across four orientations. Thus a decrease in firing rates could not explain the drop in correlation strength we observed with RF gratings, but it could contribute to the measurement with annular gratings, which slightly suppressed responses below the spontaneous firing rate (to $6.061 \pm 0.029$ and $5.989 \pm$ $0.028 \mathrm{~Hz}$ for the near and far annulus, respectively; $p \ll 0.001$ for both comparisons to spontaneous rate; $p=0.5$ for comparison between annuli; Fig. 3, bottom). To be sure that the decorrelation was not due to weak firing rates and an underestimation of correlations, we restricted our analysis to high rate pairs - those in which both cells fired at least 3 spikes/s (we tested a range of threshold values from 1 to 5 spikes/s, and the results held throughout). We found robust decorrelation in this subset of data, similar in magnitude to that in the full dataset $\left(\Delta r_{s c}\right.$ RF: $0.03 ; \Delta r_{s c}$ near: $-0.01 ; \Delta r_{s c}$ far: -0.03 ; all $\left.p s \ll 0.001\right)$. Thus, even in pairs with robust responses, decorrelation was evident, ruling out low firing rates as an explanation for the effect.

V1 surround suppression involves feedforward, horizontal, and feedback circuitry. Because of the size of our annular gratings, it is unlikely that surround effects in the retina or thalamus contribute strongly (Angelucci and Bressloff, 2006). The contribution of horizontal and feedback circuitry can be distinguished by measurements of onset latency and its dependence on stimulus size (Bair et al., 2003; Henry et al., 2013). The propagation velocity of horizontal connections has been estimated to be $0.1-0.2$ $\mathrm{m} / \mathrm{s}$ (Bringuier et al., 1999). Our annular gratings likely drive V1 neurons located $\sim 5$ and $10 \mathrm{~mm}$ away from those recorded (Van Essen et al., 1984). Thus, we would expect delays of 25-50 and 50$100 \mathrm{~ms}$ relative to RF signals, for the near and far annulus, respectively, discounting synaptic delays for inputs from neurons too distant to reach the recorded cells directly. Feedback connections, on the other hand, are fast ( $\sim 3 \mathrm{~m} / \mathrm{s}$; Girard et al., 2001) and project extensively. Thus, there would be little delay for either annulus, and no difference between effects driven by near and far annuli.

To quantify the latency of decorrelation for each condition, we calculated $r_{s c}$ in sliding $100 \mathrm{~ms}$ windows shifted by $2 \mathrm{~ms}$ steps (Fig. 3, top). We defined the onset latency as the midpoint of the first bin with a significant difference from the spontaneous value, and we used a bootstrap procedure to quantify our confidence in this estimate (see Materials and Methods). The latency for the RF grating-driven decrease in $r_{s c}$ was $108 \mathrm{~ms}$ (99\% CI: 76-116 ms; Fig. 3, top, blue plot). For the near and far annuli, the latencies for the decrease were $110 \mathrm{~ms}$ (99\% CI: 72-124 ms; yellow) and $62 \mathrm{~ms}$ (99\% CI: 36-92 ms; red), respectively. The 99\% CIs for the pairwise differences between conditions were as follows: Near-RF: 30 to $40 \mathrm{~ms}$; Far-Near: -82 to $4 \mathrm{~ms}$; Far-RF: -62 to $8 \mathrm{~ms}$. Thus, none of the conditions differed significantly in their onset latencies (i.e., all the CIs contain zero). As mentioned above, if horizontal connections mediated the decorrelation, we would predict an onset latency delay of $\sim 25 \mathrm{~ms}$ relative to that of the RF grating in the case of the near annulus, and $50 \mathrm{~ms}$ in the case of the far annulus. While we cannot rule out the possibility that the decorrelation caused by the near annulus is delayed $25 \mathrm{~ms}$ relative to that caused by the RF grating (the CI for this comparison contains $25 \mathrm{~ms}$ ), we can reject the hypothesis that the effect of the far annulus is delayed by $50 \mathrm{~ms}$ relative to the RF grating (the CI does not contain $50 \mathrm{~ms}$ ). The lack of a significant latency difference between the RF grating and the annuli, and between the two annuli, suggests a more important contribution from feedback than horizontal connections.

Our quantification of onset latency is based on crossing a statistical significance threshold, and thus sensitive to the magnitude and variability of changes in correlations. We therefore also computed onset latency by fitting a piecewise-linear function to the correlation time series of each pair. The pattern of results was qualitatively unchanged.

We next asked whether the strength of surround suppression in each pair was related to the magnitude of the annulus-driven decorrelation. To measure surround suppression, we included a $12^{\circ}$ grating in our stimulus ensemble in three of the five array 

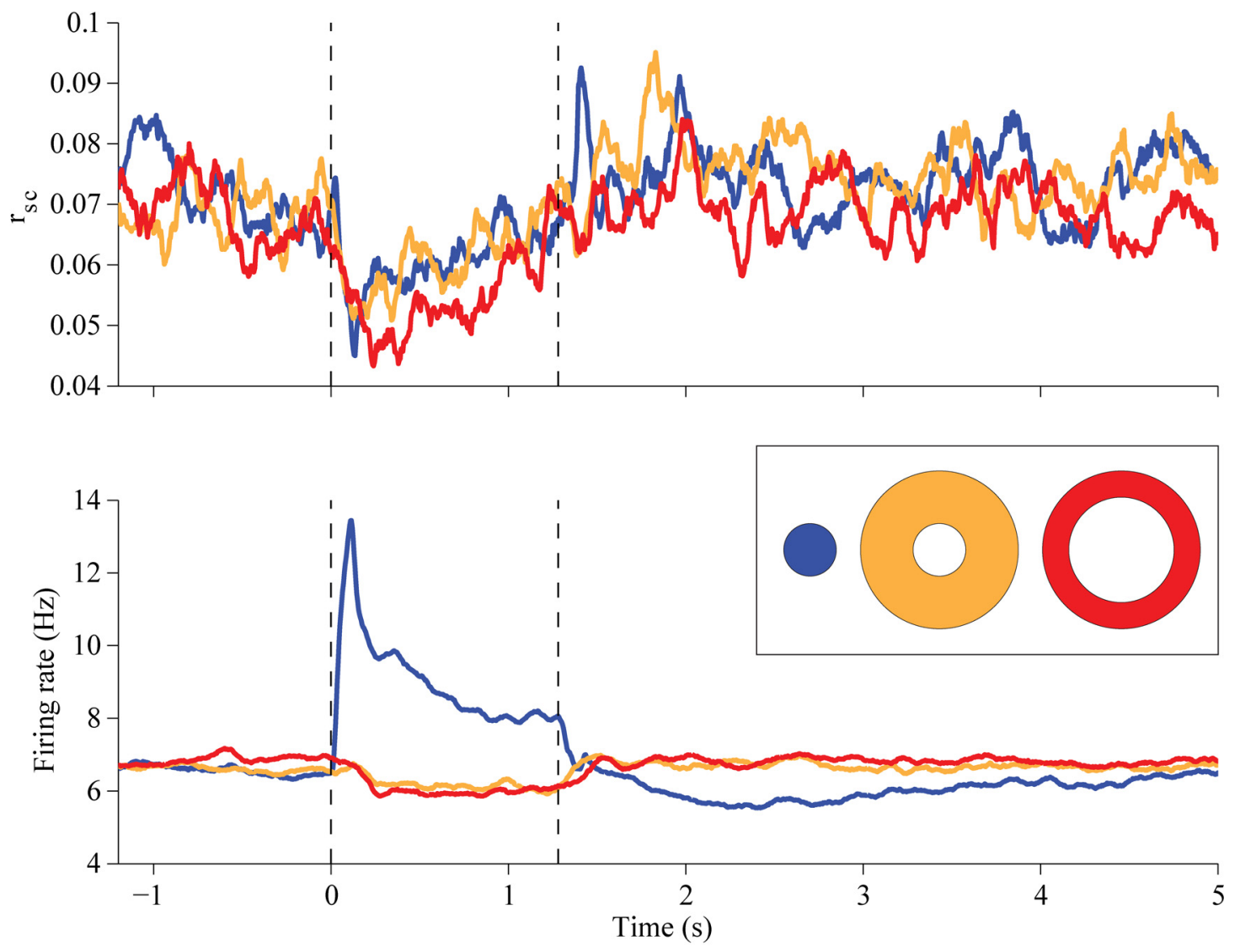

Figure 3. Temporal dynamics of $r_{s c}$ and firing rates. Top, The value of $r_{s c}$ was measured in successive $100 \mathrm{~ms}$ time bins; data points are plotted at the midpoints of these bins. Blue line indicates responses to RF grating, yellow to the near annulus, and red to the far annulus. Vertical lines indicate the onset (at time 0 ) and offset (1.28) of the visual stimulus. Data are based on all 14,360 pairs. Bottom, Corresponding individual neuronal firing rates analyzed and presented as above.

implants comprising the main dataset. We calculated a surround suppression index (SI) as the difference in response between the RF grating and the $12^{\circ}$ grating (Cavanaugh et al., 2002), divided by the response to the RF grating:

$$
S I=\frac{R_{r f}-R_{12^{\circ}}}{R_{r f}} .
$$

When calculating SI, we considered only the grating orientation that maximally excited each neuron. We also only considered cells for which the firing rate to the RF grating increased by $>2$ SDs above baseline, to minimize potential floor effects. We then averaged the SI values across the two cells comprising each pair.

The average SI across the 185 qualifying neurons was 0.18 ( \pm 0.014 SEM $)$. Previous studies have reported average SI values of $\sim 0.4$ (Cavanaugh et al., 2002). The weaker suppression that we observed is likely due to our RF grating covering the aggregate RF of all the recorded neurons. Since this $4^{\circ}$ grating was much larger than a typical $\sim 1^{\circ} \mathrm{V} 1 \mathrm{RF}$ at our recording eccentricity (Cavanaugh et al., 2002), the neurons were likely already suppressed by the RF grating, leading to an underestimate of the true strength of suppression. Nevertheless, we did observe clear surround suppression in our sample of neurons.

We examined the relationship between SI and the average change in $r_{s c}$ caused by the near annulus (across all orientations), reasoning that if decorrelation and surround suppression relied on shared mechanisms then there would be an inverse relationship in these values. We found that the magnitude of the decrease in $r_{s c}$ was not related to SI (Pearson's $r=-0.06, t_{(183)}=-0.76$;

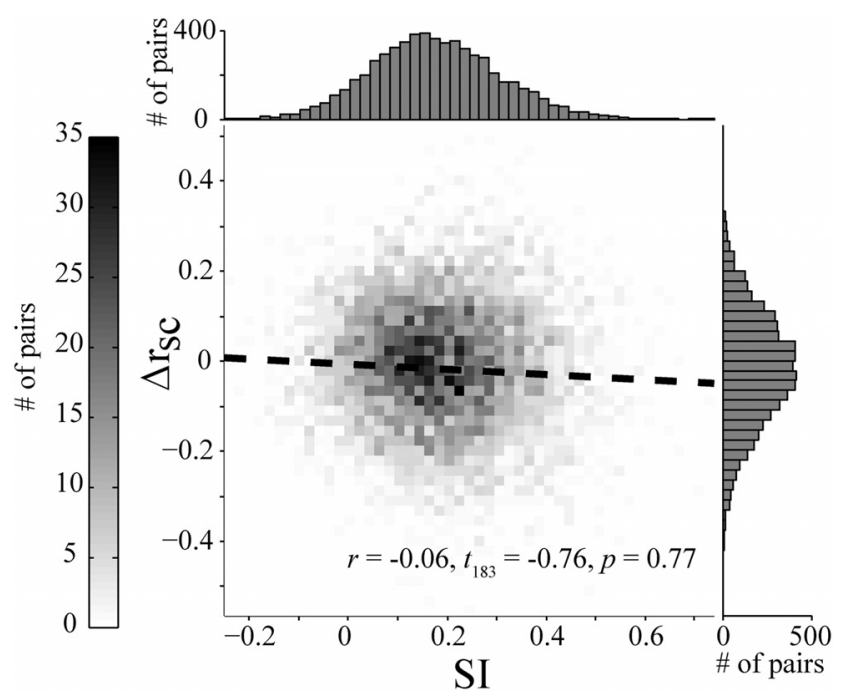

Figure 4. Relationship between surround-suppression index (SSI) and $r_{s c}$ modulation $\left(\Delta r_{s c}\right)$. The dashed line indicates the best linear fit (in a least-squares sense). Top and right, Depict the marginal histograms for the SSI and $\Delta r_{s c}$ distributions, respectively. Note that the drop in correlation here is less than that for the full dataset, but is significant $(p \ll 0.001)$.

$p=0.77$; Fig. 4). We obtained similar results when we performed this analysis only on pairs of neurons with matched orientation preferences and considering only the near annulus having their preferred orientation. Restricting the analysis to pairs of cells with similar suppression indices also provided similar results. Thus, 
despite most pairs showing both a decrease in $r_{s c}$ and firing rate by stimulation of the surround, the magnitude of these two effects were largely independent. The lack of a clear relationship between surround suppression and the drop in correlations caused by an annulus suggests that the decorrelation may involve a more distributed effect than the suppression provided directly to the pair of neurons.

We showed that stimulation of the RF and the surround each reduces correlations in V1. The inclusion of the large grating condition positioned us to assess whether these effects might be combined. Consistent with this suggestion, we found the magnitude of decorrelation caused by the large grating $\left(\Delta r_{s c}=\right.$ $-0.046 \pm 0.010, p \ll 0.001)$ was significantly greater than that caused by the RF grating $\left(\Delta r_{s c}=-0.006 \pm 0.011\right)$ for the three implants for which we collected both conditions (paired-samples $t$ test: $p=0.002$ ). Thus, providing drive to the surround decorrelates responses to the RF stimulus. It was possible that the decrease in firing rate caused by surround suppression to the large grating relative to the RF grating could have led to this reduction in correlations. As with our main analysis above, we also reexamined the data after excluding neurons with average firing rates $<3 \mathrm{~Hz}$. We found that the decorrelation induced by the large grating remained above that induced by the RF grating for this subset of high firing rate neurons $(p=0.011)$.

Finally, we investigated whether the decorrelation caused by stimulation beyond the RF was due to spatially specific network interactions or to a more global mechanism. To distinguish between these possibilities, we compared the effects of stimuli in the ipsilateral hemifield to gratings presented over the aggregate RF. If the ipsilateral stimuli, which provide drive to the contralateral hemisphere, also reduced correlations, this would suggest a global mechanism. For this experiment, we collected data from 64 neurons in one array implant, providing 2016 pairs.

As in the primary experiment, $r_{s c}$ was weaker during stimulation of the RF (baseline: $r_{s c}=0.186 \pm 0.023$; stimulus: $r_{s c}=$ $0.164 \pm 0.016$; two-tailed paired-samples $t$ test: $p \ll 0.001)$. In contrast, $r_{s c}$ did not change during stimulation of the ipsilateral hemifield (baseline: $r_{s c}=0.172 \pm 0.023$; stimulus: $r_{s c}=0.170 \pm$ $0.023 ; p=0.7)$. As expected, the firing rate increased during stimulation of the RF (prestimulus: $7.036 \pm 0.782 \mathrm{~Hz}$; stimulus: $10.278 \pm 1.158 \mathrm{~Hz} ; p=0.022$ ), but did not change during ipsilateral stimulation (prestimulus: $6.967 \pm 0.784 \mathrm{~Hz}$; stimulus: $6.894 \pm 0.780 \mathrm{~Hz} ; p=0.9$ ). Thus, the suppression of correlations by stimuli delivered outside the RF only occurs for inputs provided to the contralateral visual field.

\section{Discussion}

It has long been known that the firing rate of many V1 neurons is suppressed by stimuli placed outside the classical RF (Hubel and Wiesel, 1968), a phenomenon now commonly known as surround suppression (Angelucci and Bressloff, 2006). Here we have shown that correlations are also suppressed by stimuli in the RF surround. Remarkably, this suppression is similar to that caused by stimulating the RF directly, despite having opposite effects on neuronal firing rates.

V1 surround suppression is thought to be inherited in part from precortical structures, with important additional contributions from horizontal and feedback circuitry in cortex (Angelucci and Bressloff, 2006). The effects we report likely depend most strongly on feedback connections. First, the spatial extents of the annuli we use fall beyond the region where precortical mechanisms contribute most strongly (Angelucci and Bressloff, 2006). Second, the onset latency for decorrelation caused by surround stimulation was similar to that caused by RF stimulation, and we observed no difference in the latency of signals from the near and far annulus. This is difficult to explain with the propagation of signals via slowly conducting horizontal connections.

Surround suppression has been shown to involve a withdrawal of excitatory drive (Ozeki et al., 2009), the recruitment of inhibition (Haider et al., 2010), or both (Anderson et al., 2001). There are several possible scenarios for how these mechanisms could reduce correlations. The change in the ratio of excitation to inhibition could lead to more balanced networks (Renart et al., 2010), in which spiking correlations are reduced by the coordination between inhibitory and excitatory inputs. Stimulation of the surround, like the RF, may also cause decorrelation by "stabilizing" spontaneous fluctuations in the activity of clustered groups of neurons (Litwin-Kumar and Doiron, 2012). Alternatively, the withdrawal of excitation may involve a loss of inputs shared with other nearby cells, resulting in weaker correlations. Finally, the recruitment of suppression may make cells intrinsically less sensitive to shared fluctuations in their input. The slow timescale correlations we measured here likely arise from lowfrequency fluctuations in shared inputs; if surround-mediated inputs lower the input resistance of cells, this might make them less sensitive to these low-frequency signals (Kohn and Smith, 2005). However, we observed no relationship between the strength of suppression and decorrelation, on a pair-by-pair basis, arguing against this final interpretation.

Surround suppression is a form of normalization (Heeger, 1992; Schwartz and Simoncelli, 2001; Cavanaugh et al., 2002; Carandini and Heeger, 2012; Coen-Cagli et al., 2012). In this framework, the response of a neuron is proportional to the excitatory drive it receives, divided by the summed activity of a broader population of neurons. For surround suppression, the relevant pool involves neurons with offset (or larger) spatial RFs. Interestingly, other signals that modulate correlations also involve normalization. For instance, increasing stimulus contrast in the RF recruits more normalization (Carandini et al., 1997) and reduces long timescale correlations (Kohn and Smith, 2005; Huang and Lisberger, 2009; Tan et al., 2014). Increasing the size of a high-contrast grating, like presenting annular gratings, recruits additional normalization from the surround and weakens long timescale correlations further, as shown here and in data of Jia et al., 2013 (unpublished analysis). Attentional modulation also involves normalization (Reynolds and Heeger, 2009; Sundberg et al., 2009; Lee and Maunsell, 2010; Ni et al., 2012; Schwartz and Coen-Cagli, 2013) and it too weakens correlations (Cohen and Maunsell, 2009; Mitchell et al., 2009). Finally, adaptation may affect normalization signals (Wainwright et al., 2002; Wissig and Kohn, 2012), and it also alters correlations (Gutnisky and Dragoi, 2008; Adibi et al., 2013). Note that although these many different forms of modulation have been cast as involving normalization, they may involve distinct cellular and circuit processes. Nevertheless, together these findings suggest a framework for understanding the mechanisms that control the strength of correlations, namely that they may be tightly related to those involved in normalization.

Surround suppression is a well known form of spatial contextual modulation in vision, which has been linked to a number of perceptual and computational phenomena, like figure-ground segregation (Lamme, 1995; Zhou et al., 2000), contour completion (Field et al., 1993; Li et al., 2008), and salience (Itti and Koch, 2000; Li, 2002; Coen-Cagli et al., 2012). This literature has focused on the effects of surround stimuli on the firing rate of individual neurons. Our results show that surround stimuli can also alter the coordination of activity within a neuronal population. This may influence the coding performance of that popula- 
tion (Averbeck et al., 2006), or the strength of the input it provides to downstream circuits. Thus, a full understanding of how surround contextual effects contribute to visual processing will likely require a greater appreciation and understanding of their effect on population coordination.

\section{References}

Adibi M, McDonald JS, Clifford CW, Arabzadeh E (2013) Adaptation improves neural coding efficiency despite increasing correlations in variability. J Neurosci 33:2108-2120. CrossRef Medline

Anderson JS, Lampl I, Gillespie DC, Ferster D (2001) Membrane potential and conductance changes underlying length tuning of cells in cat primary visual cortex. J Neurosci 21:2104-2112. Medline

Angelucci A, Bressloff PC (2006) Contribution of feedforward, lateral and feedback connections to the classical receptive field center and extraclassical receptive field surround of primate V1 neurons. Prog Brain Res 154:93-120. CrossRef Medline

Averbeck BB, Latham PE, Pouget A (2006) Neural correlations, population coding and computation. Nat Rev Neurosci 7:358-366. CrossRef Medline

Bair W, Cavanaugh JR, Movshon JA (2003) Time course and time-distance relationships for surround suppression in macaque V1 neurons. J Neurosci 23:7690-7701. Medline

Bringuier V, Chavane F, Glaeser L, Frégnac Y (1999) Horizontal propagation of visual activity in the synaptic integration field of area 17 neurons. Science 283:695-699. CrossRef Medline

Carandini M, Heeger DJ (2012) Normalization as a canonical neural computation. Nat Rev Neurosci 13:51-62. CrossRef Medline

Carandini M, Heeger DJ, Movshon JA (1997) Linearity and normalization in simple cells of the macaque primary visual cortex. J Neurosci 17:86218644. Medline

Cavanaugh JR, Bair W, Movshon JA (2002) Nature and interaction of signals from the receptive field center and surround in macaque V1 neurons. J Neurophysiol 88:2530-2546. CrossRef Medline

Coen-Cagli R, Dayan P, Schwartz O (2012) Cortical surround interactions and perceptual salience via natural scene statistics. PLoS Comput Biol 8:e1002405. CrossRef Medline Cohen MR, Kohn A (2011) Measuring and interpreting neuronal correlations. Nat Neurosci 14:811-819. CrossRef Medline

Cohen MR, Maunsell JH (2009) Attention improves performance primarily by reducing interneuronal correlations. Nat Neurosci 12:1594-1600. CrossRef Medline

de la Rocha J, Doiron B, Shea-Brown E, Josić K, Reyes A (2007) Correlation between neural spike trains increases with firing rate. Nature 448:802 806. CrossRef Medline

Field DJ, Hayes A, Hess RF (1993) Contour integration by the human visual system: evidence for a local "association field." Vision Res 33:173-193. CrossRef Medline

Girard P, Hupé JM, Bullier J (2001) Feedforward and feedback connections between areas V1 and V2 of the monkey have similar rapid conduction velocities. J Neurophysiol 85:1328-1331. Medline

Gu Y, Liu S, Fetsch CR, Yang Y, Fok S, Sunkara A, DeAngelis GC, Angelaki DE (2011) Perceptual learning reduces interneuronal correlations in macaque visual cortex. Neuron 71:750-761. CrossRef Medline

Gutnisky DA, Dragoi V (2008) Adaptive coding of visual information in neuronal populations. Nature 452:220-224. CrossRef Medline

Haider B, Krause MR, Duque A, Yu Y, Touryan J, Mazer JA, McCormick DA (2010) Synaptic and network mechanisms of sparse and reliable visual cortical activity during nonclassical receptive field stimulation. Neuron 65:107-121. CrossRef Medline

Heeger DJ (1992) Half-squaring in responses of cat striate cells. Vis Neurosci 9:427-443. CrossRef Medline

Henry CA, Joshi S, Xing D, Shapley RM, Hawken MJ (2013) Functional characterization of the extraclassical receptive field in macaque V1: contrast, orientation, and temporal dynamics. J Neurosci 33:6230-6242. CrossRef Medline

Huang X, Lisberger SG (2009) Noise correlations in cortical area MT and their potential impact on trial-by-trial variation in the direction and speed of smoothpursuit eye movements. J Neurophysiol 101:3012-3030. CrossRef Medline

Hubel DH, Wiesel TN (1968) Receptive fields and functional architecture of monkey striate cortex. J Physiol 195:215-243. Medline
Itti L, Koch C (2000) A saliency-based search mechanism for overt and covert shifts of visual attention. Vision Res 40:1489-1506. CrossRef Medline

Jeanne JM, Sharpee TO, Gentner TQ (2013) Associative learning enhances population coding by inverting interneuronal correlation patterns. Neuron 78:352-363. CrossRef Medline

Jia X, Tanabe S, Kohn A (2013) Gamma and the coordination of spiking activity in early visual cortex. Neuron 77:762-774. CrossRef Medline

Kelly RC, Smith MA, Samonds JM, Kohn A, Bonds AB, Movshon JA, Lee TS (2007) Comparison of recordings from microelectrode arrays and single electrodes in the visual cortex. J Neurosci 27:261-264. CrossRef Medline

Kohn A, Smith MA (2005) Stimulus dependence of neuronal correlation in primary visual cortex of the macaque. J Neurosci 25:3661-3673. CrossRef Medline

Kohn A, Zandvakili A, Smith MA (2009) Correlations and brain states: from electrophysiology to functional imaging. Curr Opin Neurobiol 19:434438. CrossRef Medline

Lamme VA (1995) The neurophysiology of figure-ground segregation in primary visual cortex. J Neurosci 15:1605-1615. Medline

Lee J, Maunsell JH (2010) Attentional modulation of MT neurons with single or multiple stimuli in their receptive fields. J Neurosci 30:3058-3066. CrossRef Medline

Li W, Piëch V, Gilbert CD (2008) Learning to link visual contours. Neuron 57:442-451. CrossRef Medline

Li Z (2002) A saliency map in primary visual cortex. Trends Cogn Sci 6:9_ 16. CrossRef Medline

Litwin-Kumar A, Doiron B (2012) Slow dynamics and high variability in balanced cortical networks with clustered connections. Nat Neurosci 15: 1498-1505. CrossRef Medline

Mitchell JF, Sundberg KA, Reynolds JH (2009) Spatial attention decorrelates intrinsic activity fluctuations in macaque area V4. Neuron 63:879888. CrossRef Medline

Ni AM, Ray S, Maunsell JH (2012) Tuned normalization explains the size of attention modulations. Neuron 73:803-813. CrossRef Medline

Olkin I (1981) Range restrictions for product-moment correlation matrices. Psychometrika 46:469-472. CrossRef

Ozeki H, Finn IM, Schaffer ES, Miller KD, Ferster D (2009) Inhibitory stabilization of the cortical network underlies visual surround suppression. Neuron 62:578-592. CrossRef Medline

Renart A, de la Rocha J, Bartho P, Hollender L, Parga N, Reyes A, Harris KD (2010) The asynchronous state in cortical circuits. Science 327:587-590. CrossRef Medline

Reynolds JH, Heeger DJ (2009) The normalization model of attention. Neuron 61:168-185. CrossRef Medline

Schwartz O, Coen-Cagli R (2013) Visual attention and flexible normalization pools. J Vis 13(1): pii: 25. CrossRef Medline

Schwartz O, Simoncelli EP (2001) Natural signal statistics and sensory gain control. Nat Neurosci 4:819-825. CrossRef Medline

Smith MA, Kohn A (2008) Spatial and temporal scales of neuronal correlation in primary visual cortex. J Neurosci 28:12591-12603. CrossRef Medline

Smith MA, Bair W, Movshon JA (2002) Signals in macaque striate cortical neurons support the perceptions of glass patterns. J Neurosci 22:83348345. Medline

Sundberg KA, Mitchell JF, Reynolds JH (2009) Spatial attention modulates center-surround interactions in macaque visual area V4. Neuron 61:952963. CrossRef Medline

Tan AY, Chen Y, Scholl B, Seidemann E, Priebe NJ (2014) Sensory stimulation shifts visual cortex from synchronous to asynchronous states. Nature 509:226-229. CrossRef Medline

Van Essen DC, Newsome WT, Maunsell JH (1984) The visual field representation in striate cortex of the macaque monkey: asymmetries, anisotropies, and individual variability. Vision Res 24:429-448. CrossRef Medline

Wainwright MJ, Schwartz O, Simoncelli EP (2002) Natural image statistics and divisive normalization: modeling nonlinearity and adaptation in cortical neurons. In: Probabilistic models of the brain: perception and neural function (Rao R, Olshausen B, Lewicki M, eds.), pp 203-222. Cambridge, MA: MIT.

Wissig SC, Kohn A (2012) The influence of surround suppression on adaptation effects in primary visual cortex. J Neurophysiol 107:3370-3384. CrossRef Medline

Zhou H, Friedman HS, von der Heydt R (2000) Coding of border ownership in monkey visual cortex. J Neurosci 20:6594-6611. Medline 